\title{
DETERMINING THERMAL DIFFUSIVITY AND DEFECT ATTRIBUTES IN CERAMIC MATRIX COMPOSITES BY INFRARED IMAGING*
}

\author{
S. Ahuja, W. A. Ellingson, J. Stuckey and E. R. Koehl \\ Energy Technology Division \\ Argonne National Laboratory \\ Argonne $\Pi$ L 60439-4825
}

The submitted manuscript has been authored by a contractor of the U.S. Government under contract No. W-31-109-ENG-38. Accordingly, the U.S. Government retains a nonexclusive, royaltyfree license to publish or reproduce the published form of this contribution, or allow others to do so, for U.S. Govemment purposes.

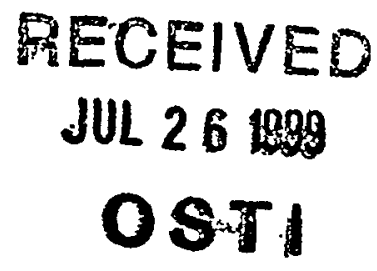

\begin{abstract}
Ceramic matrix composites are being developed for numerous high temperature applications, including rotors and combustors for advanced turbine engines, heat exchanger and hot-gas filters for coal gasification plants. Among the materials of interest are silicon-carbide-fiber-reinforced-silicon-carbide $\left(\mathrm{SiC}_{(\mathrm{f})} / \mathrm{SiC}\right)$, silicon-carbide-fiber-reinforced-silicon-nitride $\left(\mathrm{SiC}_{(\mathrm{f})} / \mathrm{Si}_{3} \mathrm{~N}_{4}\right)$, aluminum-oxide-reinforced-alumina $\left(\mathrm{Al}_{2} \mathrm{O}_{3}\left(\mathrm{f} / \mathrm{Al}_{2} \mathrm{O}_{3}\right)\right.$, etc. In the manufacturing of these ceramic composites, the conditions of the fiber/matrix interface are critical to the mechanical and thermal behavior of the component. Defects such as delaminations and non-uniform porosity can directly effect the performance. A nondestructive evaluation (NDE) method, developed at Argonne National Laboratory has proved beneficial in analyzing as-processed conditions and defect detection created during manufacturing. This NDE method uses infrared thermal imaging for full-field quantitative measurement of the distribution of thermal diffusivity in large components. Intensity transform algorithms have been used for contrast enhancement of the output image. Nonuniformity correction and automatic gain control are used to dynamically optimize video contrast and brightness, providing additional resolution in the acquired images. Digital filtering, interpolation, and least-squares-estimation techniques have been incorporated for noise reduction and data acquisition. The Argonne NDE system has been utilized to determine thermal shock damage, density variations, and variations in fiber coating in a full array of test specimens.
\end{abstract}

\section{INTRODUCTION}

Continuous fiber ceramic matrix composites (CFCCs) make up a material system that can meet the demands of structural materials that are lighter, stronger, more corrosion resistant, and capable of reliable performance at elevated temperatures in energy-related industrial technologies. CFCCs are under development for high strength and stability at high temperatures. For example, the high-temperature strengths of advanced metal alloys such as Inconel-625, Incoloy-800, and 310 stainless steel decrease sharply above $500^{\circ} \mathrm{C}\left(1000^{\circ} \mathrm{F}\right)$ but a SiC (fiber)/SiC (matrix) CFCC maintains strength above $1200-1300^{\circ} \mathrm{C}$ $\left(2500^{\circ} \mathrm{F}\right)$. CFCC applications in heat exchanger tubing or other components depend on heat transfer for designed operation. Variations in thermal conductivity or thermal diffusivity caused by variations in matrix density or poor fiber distribution can affect the efficiency of service operation. Localized variations in thermal conductivity affect thermal efficiencies in such applications and cause localized thermal stresses that may be detrimental to structural performance or may cause failure. When CFCC materials are exposed to very rapid temperature changes, such as in gas turbines, thermal shock damage may occur.

\footnotetext{
*Work supported by the U.S. Department of Energy, Energy Efficiency and Renewable Energy, Office of Industrial Technologies, under Contract W-31-109-ENG-88.
} 


\section{DISCLAIMER}

This report was prepared as an account of work sponsored by an agency of the United States Government. Neither the United States Government nor any agency thereof, nor any of their employees, make any warranty, express or implied, or assumes any legal liability or responsibility for the accuracy, completeness, or usefulness of any information, apparatus, product, or process disclosed, or represents that its use would not infringe privately owned rights. Reference herein to any specific commercial product, process, or service by trade name, trademark, manufacturer, or otherwise does not necessarily constitute or imply its endorsement, recommendation, or favoring by the United States Government or any agency thereof. The views and opinions of authors expressed herein do not necessarily state or reflect those of the United States Government or any agency thereof. 


\section{DISCLAIMER}

Portions of this document may be illegible in electronic image products. Images are produced from the best available original document. 
Potential applications of CFCC materials have been reviewed [1] and it is clear that successful development of these materials requires nondestructive evaluation (NDE) methods to measure and characterize distributed properties. Examples of properties of interest are thermal diffusivity and uniformity of density in order verify process reliability and mechanical properties. Further, NDE can help provide information to feed into lifetime prediction models. Interpretation of NDE data is related to the specific CFCC: fabrication process and pore geometry, pore size, and pore distributions [2], and mechanical behavior such as reaction to thermal shock, are all dependent upon fiber architecture.

Density gradients in as-infiltrated final components are extremely important in CFCC materials, because previous studies have shown correlations between density and fracture strength [3]. For two dimensional (2D) cloth lay-up of CFCCs, delaminations between layers are of concern, and detection by NDE depends upon the material system, e.g., nonoxide/nonoxide or oxide/oxide, and the degree of the disbond or delamination.

The expected applications of advanced materials usually involve elevated temperatures in severe environments. During operation, the fiber/matrix bond quality changes and thus NDE methods are used to quantify the changes. One such change is the thermal diffusivity of the material. For example, it has been shown [4] that for reaction bonded silicon nitride (RBSN) in a uniaxially reinforced CFCC that uses Textron SCS-6 filaments, long-term exposure to oxidation results in such a significant change in thermal diffusion that we can use infrared imaging to detect the loss of interfacial bond.

For CFCCs that are prepared by tape casting, winding, or other layering processes, delaminations or planar flaws are formed in inadequately bonded successive layers. Depending on the direction of the plane of delamination, this can lead to poor reliability because of reduced mechanical or thermal properties. In this paper, $\mathrm{x}$-ray computed tomography and infrared imaging has been utilized to detect delaminations in CFCC materials. Because thermal diffusion is related to local density, any air gap (such as a delamination) is detected by differences in local thermal conductivity. Through study of pulsed thermal analysis, together with use of a sensitive detector such as current state-of-the-art infrared systems, delaminations are detected by measuring differences in thermal diffusion.

\section{EXPERIMENTAL DETAILS}

In this work, an infrared (IR) imaging technique has been used to measure thermal diffusivity of SiC/SiC CFCC specimens and components. A schematic diagram of the thermal imaging system is shown in Fig. 1 and is described in earlier papers [4-6]. The calculation of thermal diffusivity has been calculated by Parker's method [5] in which a thermal pulse of short duration is made incident on one side of the specimen and the temperature on the other side is monitored as a function of time. The front surface of the specimen was heated with a $5 \mathrm{~kJ}$ photographic flash lamp and the temperature of the back surface was measured with a scanning radiometer IR camera. A MacOS-based computer with an on-board frame grabber was employed to receive standard RS-170 signals from the IR camera, digitize, and then process each image. The inhouse developed software extracted the average gray-scale value that represented the specimen temperature. The theoretically predicted back-surface temperature $T$ as a function of time $t$ and specimen thickness $L$ according to Parker et al. [7] is given by

$$
T(L, t)=\frac{Q}{\rho C L}\left[1+2 \sum_{n=1}^{\infty}(-1)^{n} \exp \left(\frac{-n^{2} \pi^{2}}{L^{2}} \alpha t\right)\right]
$$

where $Q$ is the radiant energy incident on the front surface, $\rho$ is density, $C$ is specific heat, and $\alpha$ is thermal diffusivity. The common "half-rise time" method of determining $\alpha$ is to take $\mathrm{V}=0.5$ (when the back-surface temperature rise has reached half of its maximum) and $\omega=1.37$, thus obtaining point by point thermal diffusivity or

$$
\alpha=1.37 L^{2} / \pi^{2} t_{\frac{1}{2}} \text {. }
$$

The purpose of the autosynchronization circuit was to repeatedly fire the flash at the specific frame, thus providing a reliable time for thermal diffusivity calculations. Calculation of diffusivity requires that we know the initial temperature of the 


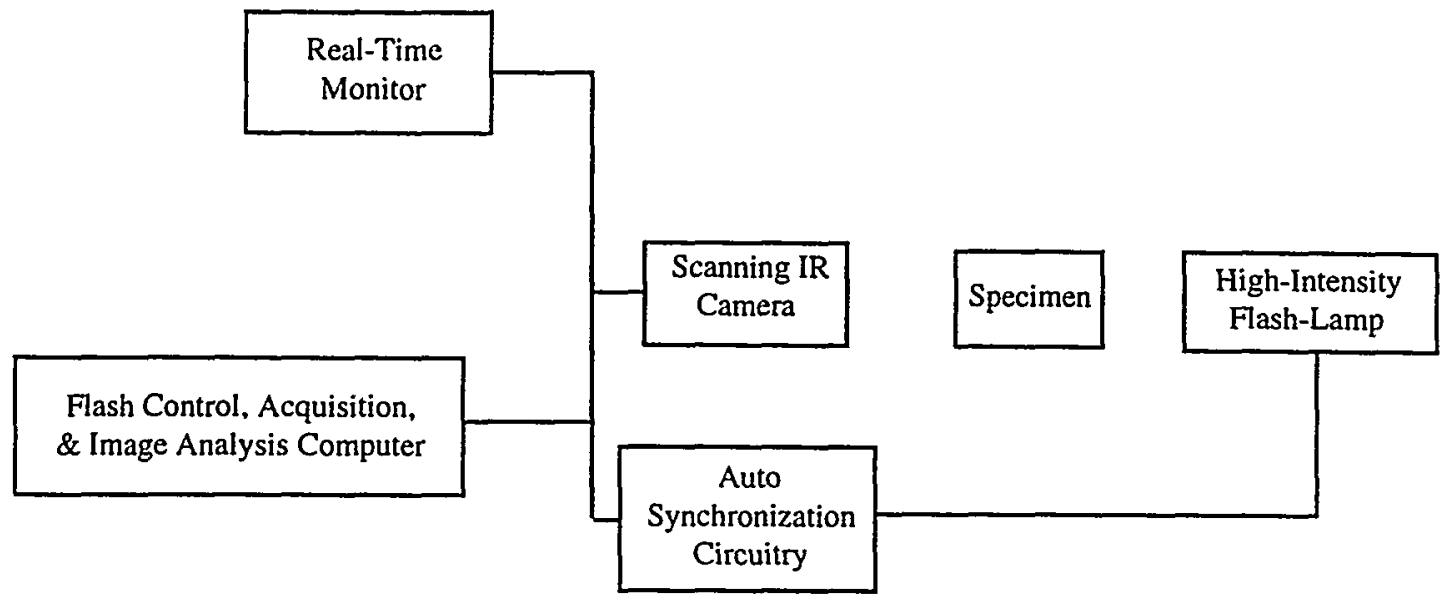

Figure 1: Schematic diagram of experimental arrangement used for thermal diffusivity imaging.

specimen, the time at which the pulse occurred, and the maximum temperature that the specimen attained. To obtain the maximum specimen temperature and to verify that the specimen attains the maximum temperature uniformly, a gray-scale distribution is determined. A temperature span of $5^{\circ} \mathrm{C}$ is typically used.

Because any noise in the temperature signal significantly alters the computed thermal diffusivity value and because scanning radiometers create a high noise levels, a noise-reduction method has been employed. To minimize the time necessary to measure thermal diffusivity, a linear least-squares fit in that vicinity was used to interpolate the value of $t_{1 / 2}$. By imaging the components at higher resolution than required, we could use spatial averaging without loss of sensitivity to the minimum defect size. A $10 \times 10$ pixel block was used, and a $512 \times 413$ pixel digitized image was transformed into a $51 \times$ 41 pixel reduced image with a substantially better signal-to-noise ratio. Also, the quarter-rise time $\left(t_{1 / 4}\right)$ and three-quarter-rise time $\left(t_{3 / 4}\right)$ were also determined for each block, where $\omega\left(t_{1 / 4}\right)=0.92$ and $\omega\left(t_{3 / 4}\right)=2.08$, according to the procedure suggested in ASTM specification E 1461-92 [8].

The thermal diffusivity values obtained at these locations were averaged with that of the $t_{1 / 2}$ value to determine effective thermal diffusivity. The thermal diffusivity from a single thermal cycle was therefore determined, thereby reducing total acquisition time. The resulting thermal diffusivity values for all $10 \times 10$ pixel subsets were assembled into diffusivity images and stored with 16-bit resolution. This avoided the need to scale each image independently (for better comparison between images) while retaining flexibility for image enhancement in the display. The system was further modified by incorporating a fully integrated, self-contained IR camera equipped with a 3-5 $\mu \mathrm{m}$ optical band-pass lens system and based on the second-generation focal plane technology. The electronics of this camera allowed the use of user-selectable intensity transform algorithms for contrast enhancement of the output image.

To verify the changes in diffusivity or through-wall porosity, $X$-ray computed tomography (CT) imaging has been used with a $160 \mathrm{KVp}$ "microfocus", in-house-built X-ray imaging system [9-10]. The system features a microfocus X-ray tube that produces a $6 \mu \mathrm{m}$ spot size. The X-rays were detected with a 9 in. image intensifier optically coupled to a CCD array. The CCD used a $1024 \times 1024$ array, thermoelectrically cooled to $-40.0^{\circ} \mathrm{C}$ and the resolution of the CCD was 14 bits, which produced multiple gray levels in the final images. Staging was accomplished with an X, Y, and theta stage controlled with stepper motors connected to a computer. The stages allowed for high accuracy in the positioning of the test object. Data were acquired by rotating the test object $360^{\circ}$, and recording several images over the entire rotation. The optimal number of images or "projections" to record was based on time factors and the size of the object being scanned. Images were taken with a set source-to-object distance at which the pixel size was $0.0065 \mathrm{~mm}$ square. By averaging multiple rows, the slice thickness of the images was found to be $0.052 \mathrm{~mm}$. The X-ray tube was set at $150 \mathrm{KVp}$. With the construction of a special density 
phantom, calibration of the density scale of the images was possible. This allowed for line profiles to measure the variations of densities across the specimen. By taking the mean of the image, an average or total density was determined.

\section{RESULTS}

The in-house-built imaging system was calibrated with graphite specimens received from the National Institute of Science and Technology, and the accuracy of the IR image analysis system was determined. The absolute value of the measured thermal diffusivity using this system deviated from the calibration value by $<5 \%$ due to thermal losses and approximations in the determination of $t / 2$.

Further, a set of 2-D Nicalon fiber/CVI SiC composites, subjected to thermal shock testing at the University of Cincinnati [11], were studied. The set consisted of five specimens that had been shocked once at quench $\Delta \mathrm{T}$ values of 200 , $400,600,800$, and $1000^{\circ} \mathrm{C}$, one unquenched specimen, one specimen that had been quenched four times at $800^{\circ} \mathrm{C}$, and a final specimen that had been air-cooled from $1000^{\circ} \mathrm{C}$. The variability rather than the quench history was highly dependent on the specimens and a higher thermal diffusivity was obtained for the $800^{\circ} \mathrm{C}$ specimen quenched four times than that of the specimen quenched only once.

The thermal diffusivity of an $\mathrm{Al}_{2} \mathrm{O}_{3} / \mathrm{Al}_{2} \mathrm{O}_{3}$ CFCC circular liner, $\approx 203 \mathrm{~mm}$ in diameter and made by the Babcock \& Wilcox Research Center, was determined. To reduce the effects of angular emissivity variation from the cylindrical surface, 12 sections (each approximately $5.0 \times 5.0 \mathrm{~cm}$ ) were imaged. Because oxides are translucent to the optical thermal excitation pulse, a problem occured because of volumetric heating. Figure 2 shows temperature/time curves for the standard $\mathrm{Al}_{2} \mathrm{O}_{3} / \mathrm{Al}_{2} \mathrm{O}_{3}$ liner and for an $\mathrm{Al}_{2} \mathrm{O}_{3} / \mathrm{Al}_{2} \mathrm{O}_{3}$ liner painted on the flashed side to render it opaque. Fig. 3 shows the defect configuration, thermal diffusivity image and the $\mathrm{X}$-ray $\mathrm{CT}$ scan of the $\mathrm{Al}_{2} \mathrm{O}_{3} / \mathrm{Al}_{2} \mathrm{O}_{3}$ liner. The $\mathrm{Al}_{2} \mathrm{O}_{3} / \mathrm{Al}_{2} \mathrm{O}_{3}$ volumetric heating curve reached a maximum temperature much later than would be expected, based on the initial thermal response. To eliminate volumetric heating, the specimens on the flashed side were therefore required to be sprayed with a graphite-based optically opaque paint. This method provided a more accurate measure of thermal variability in the specimens, and overall thermal diffusivity was seen to vary by more than a factor of 2 .

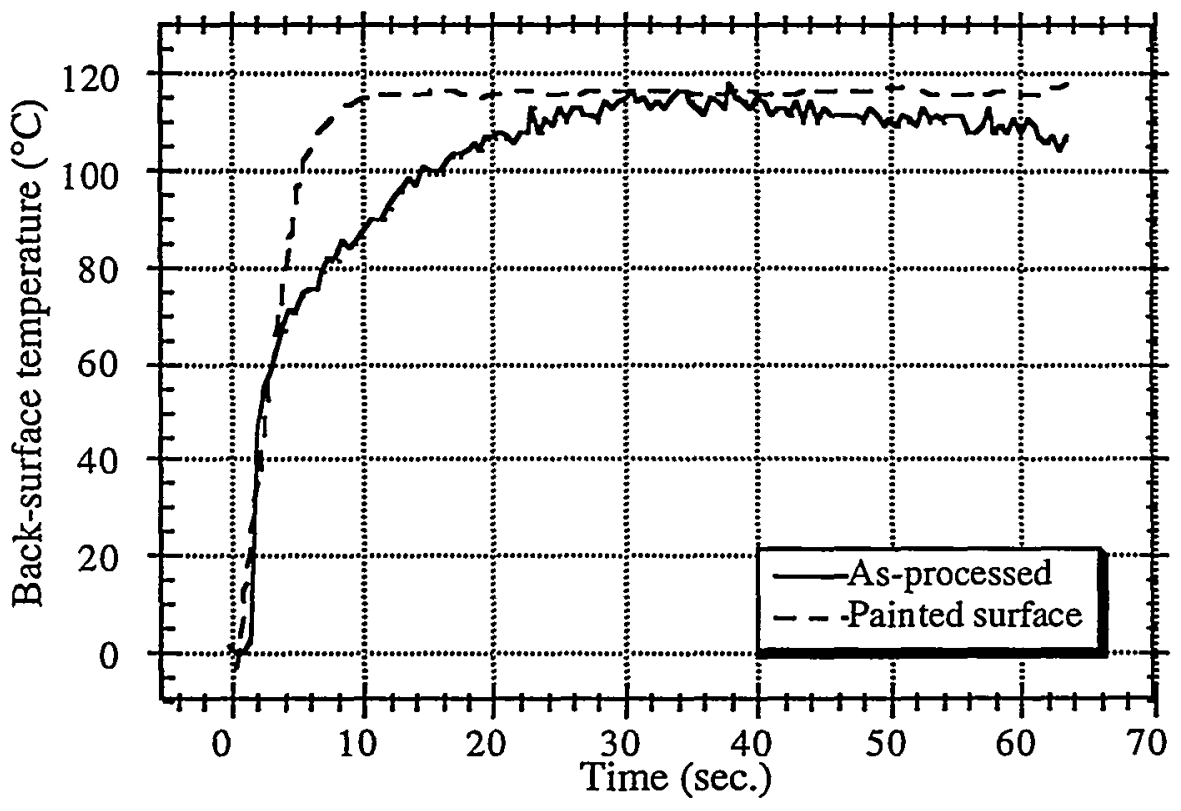

Figure 2: Surface temperature vs. time for an $\mathrm{Al}_{2} \mathrm{O}_{3} / \mathrm{Al}_{2} \mathrm{O}_{3} \mathrm{CFCC}$ in as-processed condition (volumetric heating) and with flashed surface painted to render it opaque (surface heating). 
(a)
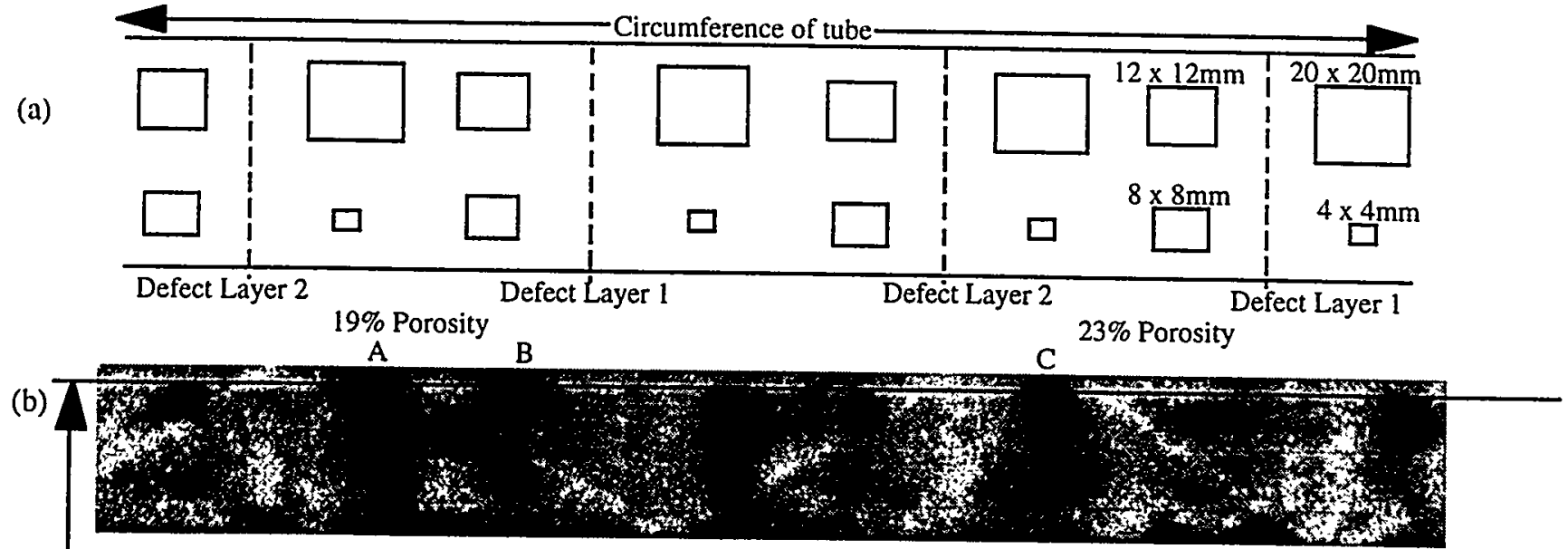

(c)

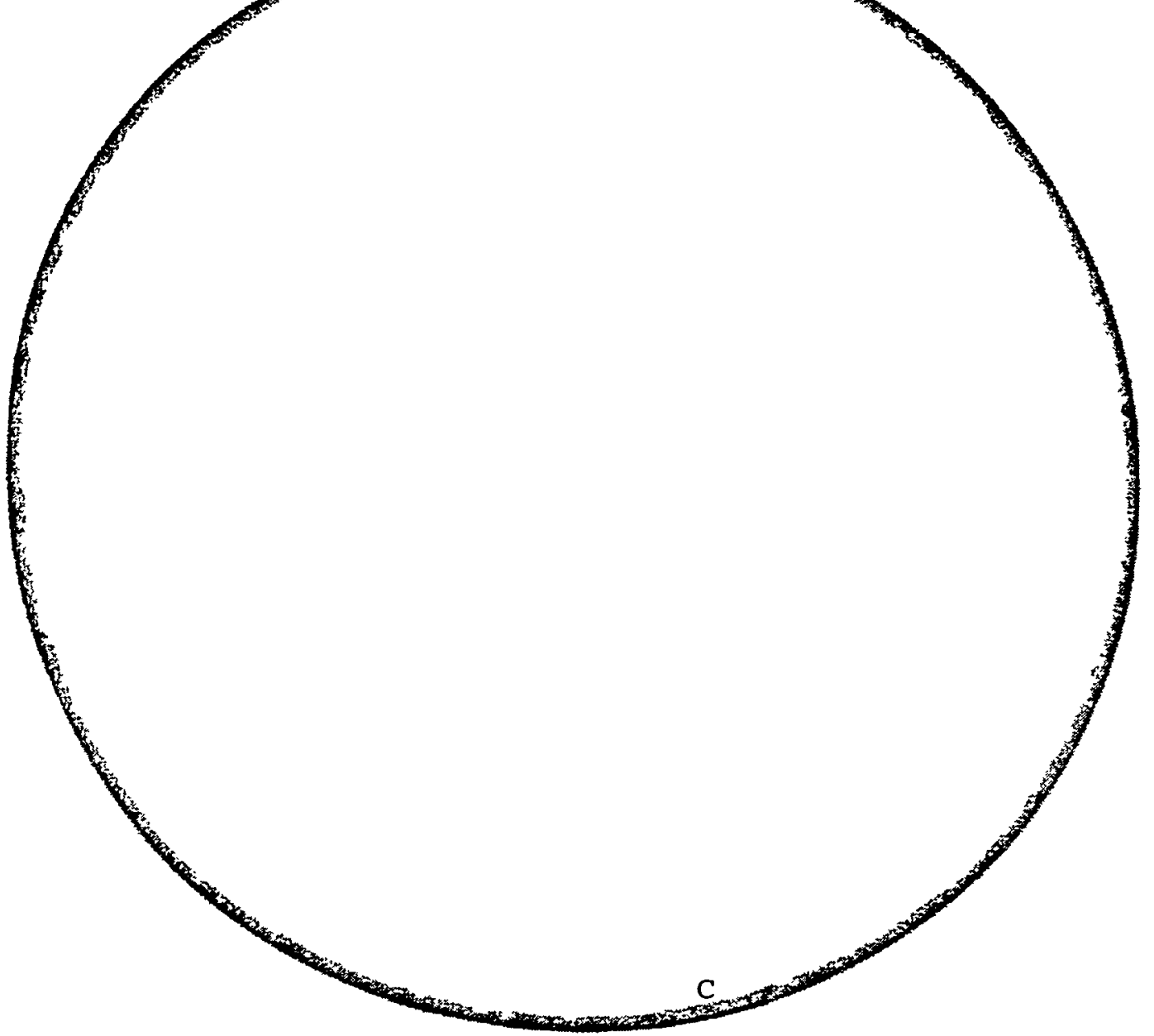

Figure 3: Correlation between thermal diffusivity image and X-ray CT scan image of Babcock and Wilcox $\mathrm{Al}_{2} \mathrm{O}_{3} / \mathrm{Al}_{2} \mathrm{O}_{3}$ filament wound NDE standard: (a) Schematic diagram of the NDE standard, (b) Thermal diffusivity image, (c) Xray $\mathrm{CT}$ image. 
A diagram provided by Babcock \& Wilcox showing the locations of the defects is given in Fig. 3(a). The ply construction was such that there were two stacked defect layers including tive helical closures and one hoop layer. Figure 3(b) shows the compiled thermal diffusivity image which corresponds directly to the defects shown in Fig. 3(a). The low and high values of thermal diffusivity are shown in the look-up table of Fig. 3(b) below the diffusivity map. Defects are shown as dark regions that correspond to low diffusivity values.

Figure 3(c) shows the acquired X-ray CT image corresponding to the cross-section of the Babcock and Wilcox $\mathrm{Al}_{2} \mathrm{O}_{3} / \mathrm{Al}_{2} \mathrm{O}_{3}$ liner, indicated by a straight line in Fig. 3(b). The voids in Fig. 3(c) have low density (black regions) and the size difference of the defects corresponding to Fig. 3(a) can be easily seen, demonstrating how X-ray tomographic imaging technology can be used to detect low-density regions. The X-ray CT method is therefore useful in verifying the thermal analysis and detect porosity and defect variations in specimens. Positions A, B, and C in Fig. 3(c) compare very well with the corresponding positions A, B. and C in Fig. 3(b).

Infrared imaging techniques were further applied to a sound $\mathrm{SiC} / \mathrm{SiC}$ combustor liner with an approximate circumference of $64 \mathrm{~cm}$, a diameter of $20 \mathrm{~cm}$, and a thickness of $3 \mathrm{~mm}$. Eleven sections per row of approximately $5.0 \times 6.5 \mathrm{~cm}$ were imaged, and the overall height of the map from top to bottom was about $15 \mathrm{~cm}$. The experimental configuration for the combustor liners and burst rings was modified in that the flash lamp was placed inside the liner while the IR camera monitored the temperature of the outside surface. Light from the flash lamp was concentrated by using aluminum foil inside the liner in an area $(\approx 100 \mathrm{~mm}$ square) centered on, but slightly larger than, the segment of interest to prevent excessive lateral thermal diffusion from the region of interest. By thus containing the area exposed to the flash, the entire liner was not heated during each flash cycle. Thus, consecutive acquisitions of time-temperature profiles for nonadjacent segments were possible without allowing the previously irradiated surface to cool completely, thereby minimizing overall acquisition time.

Figure 4 shows the diffusivity map for the $\mathrm{SiC} / \mathrm{SiC}$ combustor liner and $\mathrm{Fig} .5$ shows a gray-scale plot for one section of the diffusivity image. Thermal diffusivity images for the individual segments of the $\mathrm{SiC} / \mathrm{SiC}$ combustor liner were assembled into a single conformally mapped image, leading to faint lines between segments in the diffusivity map that are the results of acquiring images at different locations. The shallow range of diffusivity values shown at the bottom of the image is indicative of minimal defects in the liner. Thermal diffusivity mapping therefore can reveal the soundness of as-fabricated CFCCs. The gray-scale curve for one section of the diffusivity image, shown in Fig. 5, reaches a maximum that indicates the frame capture rate was long enough. Further, the smooth curve is indicative of negligible noise in the data that was acquired. For this acquisition, the temperature span setting was set to $5^{\circ} \mathrm{C}$ and was determined to be optimal for most specimens. Using the appropriate temperature range for specimens eliminated most of the noise in the gray-scale plot. Further, we determined that another way to reduce noise in the gray-scale plot was to move the flash lamp closer to the specimen, thus allowing the intense flash of light to heat the specimen to a higher temperature and providing a greater likelihood of achieving one-dimensional uniform lateral heat flow through the specimen.
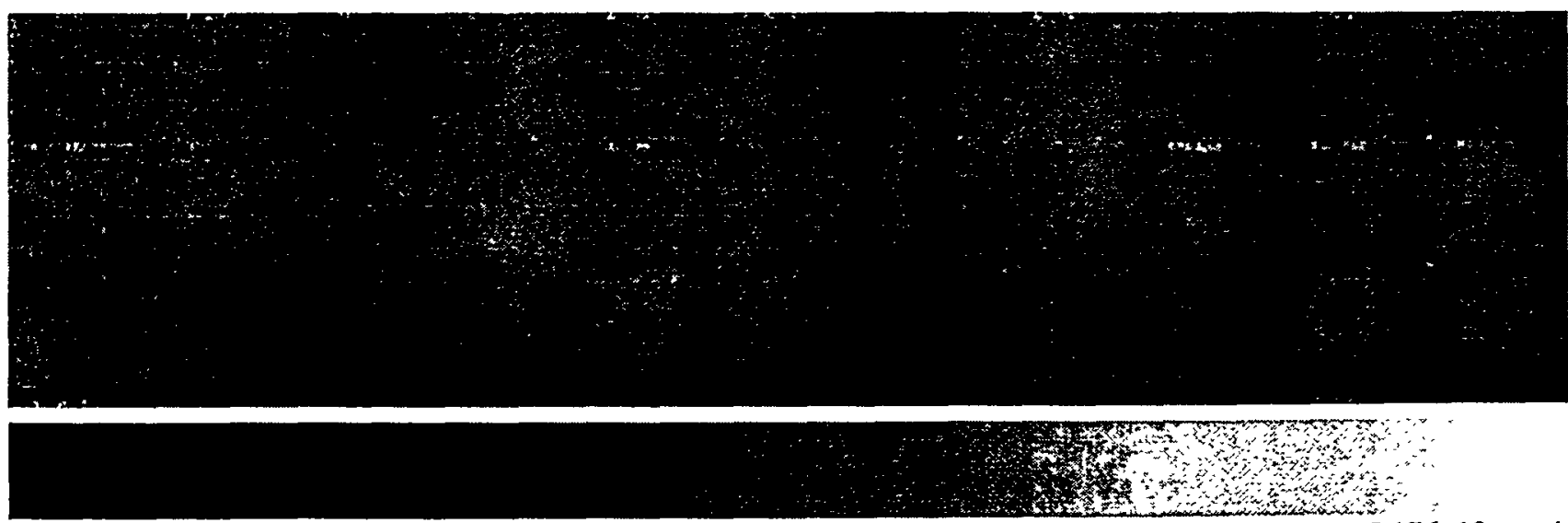

$3 \times 10.6 \mathrm{~m} 2 / \mathrm{s}$

$5.176 \times 10-6 \mathrm{~m} 2 / \mathrm{s}$

Figure 4: Thermal diffusivity image of a sound combustor liner. Values are for thermal diffusivity corresponding to the gray scale shown at bottom of image.

Page 6, Ahuja, et al. 


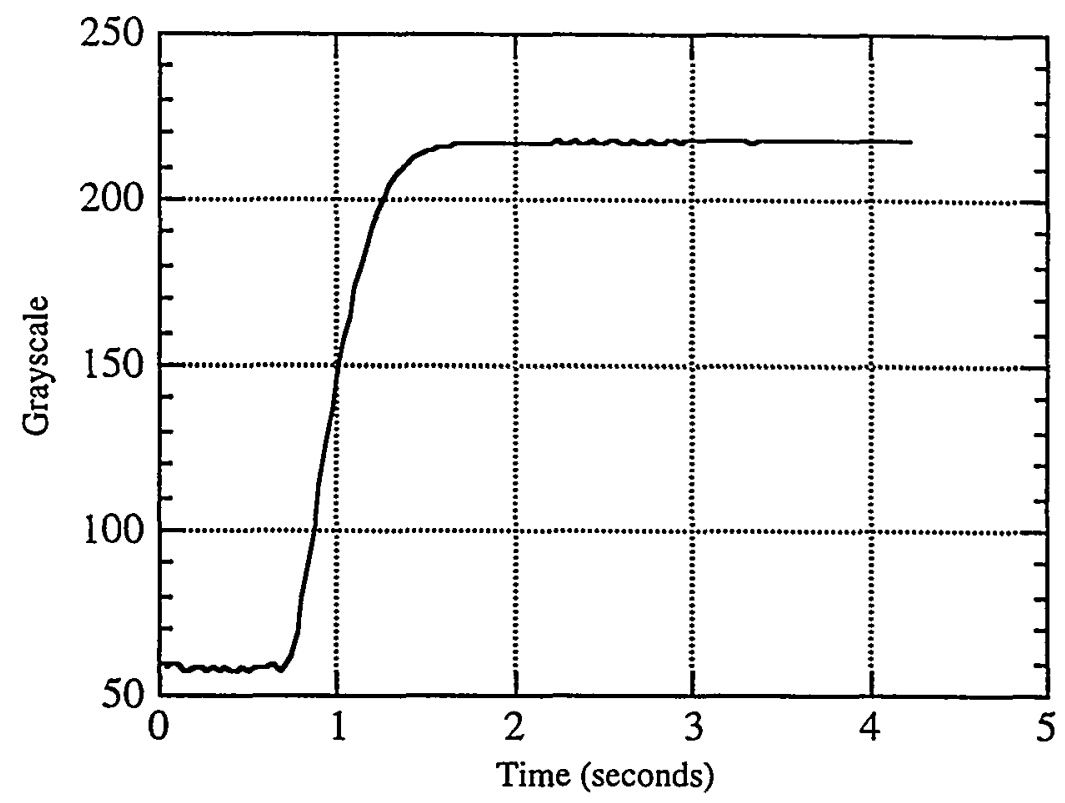

Figure 5: $\quad \mathrm{SiC} / \mathrm{SiC}$ sound combustor liner gray scale plot.

In another case, defects of various sizes were "seeded" in a $\mathrm{SiC}_{(\mathrm{f})} / \mathrm{SiC}$ composite panel made from 12 layers of 2-D plainweave Nicalon fabric (see Fig. 6). The simulated defects were created by cutting out small sections of two inner plies, replacing the fabric with Graphoil sections, and infiltrating the weave with SiC by CVI. Figure 7 shows images generated for the $\mathrm{SiC}_{(\mathrm{f})} / \mathrm{SiC}$ panel. Initially, raw thermal image were acquired at the point of maximum thermal contrast between defect and nondefect regions. Substantial image processing was then conducted on the raw image and while the defects were evident in the processed image, the relative extent of "damage" was unknown. Figure 7(a) is a thermal diffusivity image of the $\mathrm{SiC}_{(\mathrm{f})} / \mathrm{SiC}$ panel with considerably better contrast than the processed thermal images, but with average spatial resolution. Due to the quantitative nature of the thermal diffusivity images, it was possible to directly compare defect and nondefect regions with respect to different diffusivities and porosities. Dynamically adjusting the gain control and optimizing video contrast and brightness provided additional resolution in the acquired image as shown in Fig. 7(b). To acquire this image, nonuniformity correction was selected to eliminate variations in pixels in the focal plane array. Automatic gain control dynamically optimized the video contrast and brightness on a frame-by-frame basis, providing additional resolution in the acquired image.

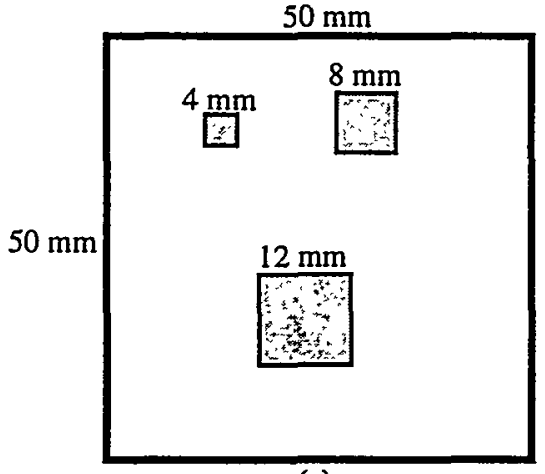

(a)

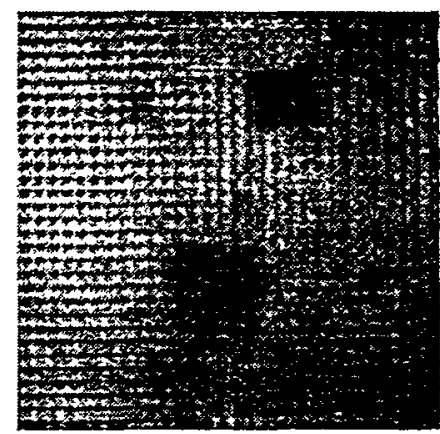

(b)

Figure 6. "Seeded" defect $\mathrm{SiC}_{(\mathrm{f})} / \mathrm{SiC}$ composite panel used for defect detection: (a) schematic diagram of specimen and defect size, and (b) through transmission $\mathrm{X}$-ray film radiograph. 


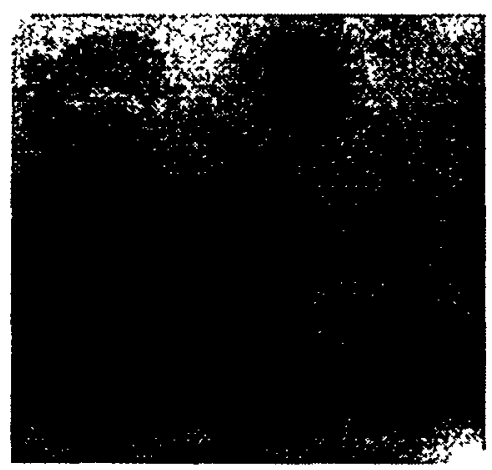

(a)

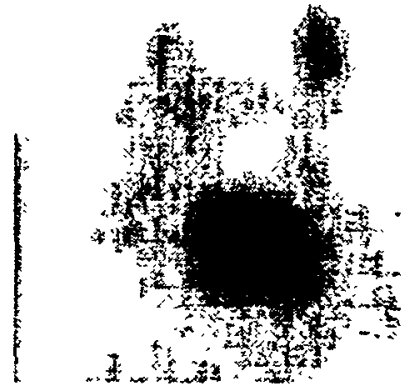

(b)

Figure 8: Images of $\mathrm{SiC}_{(\mathfrak{f})} / \mathrm{SiC}$ composite panel: (a) thermal diffusivity image, and (b) thermal diffusivity image with second-generation focal plane technology and user-selectable intensity transform algorithms for contrast enhancement of output image.

\section{CONCLUSIONS}

CFCCs prepared by layering processes have the potential for formation of delaminations or planar flaws where successive layers do not bond adequately. Nondestructive evaluation is necessary to detect and evaluate flaws such as porosity, cracks and delaminations, and to determine density gradients, reinforcement distributions, fiber/matrix interfaces, and thermal properties. An infrared camera based thermal diffusivity image system has been developed and applied to a wide range of CFCC materials and component shapes. Correlation of the data with reduction in mechanical properties on specimen subjected to thermal shock has been demonstrated. The system has been shown to be applicable to both oxides/oxides and nonoxides/nonoxides. The system has assisted in controlling the processing and assuring quality during production and fitness-for-use of manufactured CFCC components. Many specimens have been inspected for manufacturing-related defects and the data obtained by the thermal imaging method have been correlated to thermal shock, delaminations and density variations. By applying digital filtering, interpolation, and least-squares-estimation techniques for noise reduction, acquisition and analysis times of minutes or less with submillimeter spatial resolution have been achieved. In the future, fatigue damage will be correlated and methods will be investigated to allow high-temperature diffusivity measurements. Defect depths with respect to the specimen surface will be analyzed in flat and cylindrical specimens.

\section{REFERENCES}

1. Mecholsky, J. J. Jr., "Engineering Research Needs of Advanced Ceramics and Ceramic Matrix Composites," Am. Cer. Soc. Bulletin, Vol. 68, No. 2, pp. 367-375 (1989).

2. Ko, F. K., “ Preform Fiber Architecture for Ceramic Matrix Composites," Am. Cer. Soc. Bull. Vol. 68, No. 2, pp. $401-414$ (1989).

3. Caputo, A. J., Lowden, R. A. , and Stinton, D. P., "Improvements in the Fabrication of Ceramic-Fiber-Ceramic Matrix Composites by Chemical Vapor Infiltration," ORNL Report, ORNL/TM-9651, June 1985.

4. W. A. Ellingson, S. A. Rothermel, and J. F. Simpson, "Nondestructive Characterization of Ceramic Composites used as Combustor Liners in Advanced Gas Turbines", Trans. ASME, 95-GT-404, American Society of Mechanical Engineers, New York (1995).

5. J. S. Steckenrider, W. A. Ellingson, and S. A. Rothermel, "Full-Field Characterization of Thermal Diffusivity on Continuous-Fiber Ceramic Composite Materials and Components", Thermosense XVII: An International Conference on 
Thermal Sensing and Imaging Diagnostic Applications, SPIE Proceedings Vol. 2473, S. Semanovich, Ed., Bellingham, WA (1994).

6. S. Ahuja, W. A. Ellingson, J. S. Steckenrider, and S. King, "Thermal Diffusivity Imaging of Continuous Fiber Ceramic Composite Materials and Components", 23rd International Thermal Conductivity Conf., Nashville, TN, (Oct. 29-Nov. 1, 1995).

7. W. J. Parker, R. J. Jenkins, C. P. Butler and G. L. Abbott, "Flash method of determining thermal diffusivity, heat capacity, and thermal conductivity," J. Appl. Phys., Vol. 32 (9), pp. 1679-1684 (1961).

8. American Society for Testing and Materials, "Standard test method for thermal diffusivity of solids by the flash method," Annual Book of ASTM Standards, ASTM E 1461-92 (1992).

9. E. A. Sivers, W. A. Ellingson, S. A. Snyder, and D. A. Holloway, "CT Multiscan: Using Small Area Detectors to Image Large Components", Trans. ASME, 95-GT-297, American Society of Mechanical Engineers, New York (1995).

10. E. A. Sivers, "Use of multiple CT scans to accommodate large objects and stretch dynamic range of detectability", Nucl. Instrum. Meth. Phy. Res.B 99 761-764 (1995).

11. R. Singh and H. Wang, "Fracture and Damage: Thermal Shock Damage of CFCCs", Bi-monthly Periodical, Continuous Fiber Ceramic Composites Program, Oak Ridge National Laboratory, pp. $70-75$ (April-May 1994).

Page 9, Ahuja, et al. 